\title{
Towards an educational Superlnterface
}

\section{I.P.F De Diana and T.N. White}

University of Twente, The Netherlands

\begin{abstract}
It is presumed that recent technological innovations, combined with three more established (educational) technologies, could cause a drastic change in university education, if adequate organizational conditions could be created. Such conditions are needed to structure, channel and manage an as yet undreamed of flow of information. Closely related to the metaphor of the 'Info Highway', an educational 'SuperInterface' is described. Based upon networked computer platforms, such a human-computerhuman interface is to support large scale telestudy (and teleworking). The SuperInterface is to be designed or is to evolve in such a way that reliable and valid organizational foundations for university education can be established. As the organizational foundation is so paramount, the authors would like to see serious research into the modelling of SuperInterface structures, resources, and dynamics. Indications of some such research issues are presented.
\end{abstract}

Keywords: Computer networks; CSCW; Electronic books; Electronic learning environments; Groupware; Info Highway.

\section{The 'Info Highway'}

Readers of Time Magazine were probably surprised to read in the April 12 issue that their TV screens would soon give access to 'The Info Highway' (Elmer-De Witt, 1993). The Time report described an extensive plan of the U.S. Administration. The idea of an Info Highway has been strongly promoted by vice-president $\mathrm{Al}$ Gore, who laid out demands for an infrastructure for the Global Village' (Gore, 1991).

The plan intends to link most U.S. families by means of cable networks to a variety of information distributors, such as TV-networks, interactive game collections, long-distance phone service, and data banks. Cable or phone companies will take care of distribution and deliver services on demand, such as shopping catalogues, teleconferencing, video games, books and periodicals (in electronic form), news, video phone, travel services, and so on, and so on. All this is expected to have a profound influence on society.

Correspondence: Dr. Italo De Diana, Faculty of Educational Science and Technology, University of Twente, P.O. Box 217, 7500 AE Enschede, Netherlands. Email: diana@edte.utwente.nl. 
Although the technical feasibility of the plan seems to be high, the plan has to cope with a financial problem. Who will invest in establishing services, who is to pay for the services, and will the net result be profitable?

This plan is not an isolated object. Japan works on a comparable topic, and the EC is studying the development of trans-european information networks, for educational purposes amongst others.

Imagined even on a smaller scale, the impact of such mass information provisions on education could be profound. Universities, and other educational institutions, could make extensive use of information provided by tv-networks, publishers, libraries and data banks, financial services and long-distance phone service. To this we can add all the information provided by companies, who will offer access to various types of bulletin board services and electronic documents.

Even if we consider an 'Info A-road' scenario (extensive cable networks, not the full range of services available as indicated for the Info Highway) to become reality within the coming ten years, then we can expect that education will be strongly influenced. In fact, some of the (educational) technologies that will be supported by extensive cabling and cable services have already proved to be of considerable value for knowledge transfer.

We consider three such high-impact technologies: Computer Supported Collaborative (or Cooperative) Work (CSCW), Computer Based Learning (CBL), and the use of (multimedia) data bases for educational purposes. Some authors use the term 'electronic books' as a kind of shorthand for this last technology (Barker, 1990).

In mutual cooperation, these three technologies can 'embody and carry' the Info Highway from an educational point of view and can bring about quite some change in patterns of knowledge transfer in education.

\section{$\operatorname{CSCW}$}

In CSCW the computer is used to help humans to communicate and work together even though they are widely separated in distance (Greif, 1988). The computer takes care of giving access to a computer network, serves as a mailbox and electronic mail system, manages the distribution of mail, and can support teleconferencing. But even more than this, computers can support humans in the cooperative use of software applications and data, and thus allow the development of virtual workgroups that can be scattered over wide areas and work asynchronously in time (Greif \& Sarin, 1988). The communication can be made transparent by explicitly structuring it (Flores et al., 1988) and by filtering information distribution (Malone et al., 1988).

\section{$C B L$}

Since its invention, CBL has not failed to demonstrate that it can be a fascinating approach to support learning. As a learning support tool, the computer can act in various roles such as teacher, monitor, data base manager, and game provider. From the viewpoint of a teacher, CBL can 
have many faces too, such as an organized collection of learning materials and a source of learning experiences, an approach to organize and distribute teaching activities, and an approach to collect and organize information in respect to behaviour of learners. As far as learning materials are concerned, it should be noted that a long history of research on CBL has made clear that quite some teachers prefer 'open' CBL products that can be implemented, adapted, and extended, to meet local needs and conditions of use.

\section{Electronic Books}

The term Electronic Books (Barker, 1990; van Dam, 1992) refers to organized sets of datafiles (either in a database or in a hyperstructure), containing 'informal knowledge', readable and understandable by humans. The word 'informal' is used to mark a difference with formally coded knowledge, readable by machines (Gaines, 1990) ${ }^{*}$. From our point of view, informal knowledge refers in a practical sense to objects such as electronic versions of existing study, reference, and documentation material. Such knowledge can easily be stored and distributed on mass storage devices such as CD-ROM and CD-I. Distributing large amounts of information in this way can become quite cheap.

'Informal knowledge' can serve as the foundation for developing electronic study material as it becomes accessible by computer and as it can be extended and modified. Additions can serve to make the study material more accessible (annotations, cognitive routes) and to link study material with other (multimedial) information. Routing and navigation are well known from hypertext (e.g. Conklin, 1987), in which a learner, based upon marked keywords, can jump through the structure of a text and thus, in an associative way, can explore the knowledge contained in the text.

Additional knowledge could mean connections to text files, as is usual in e-mail type of applications. But other information can be linked in as well, for example computer programs. Thus, an informal knowledge base can be extended to become both a multifunctional explorable source and a multifunctional tool. Such an extendible product we will term Electronic Study Book (ESB) if the Electronic Book is intended for study purposes. Furthermore, such a book can be linked closely with e-mail and thus becomes a 'communication-based study book'.

\section{Synergy between the technologies}

These three technologies can strengthen each other considerably, especially in the setting of a networked environment intended for knowledge transfer.

The potential influence of each of them is strong. CSCW can break traditional barriers of class and school and offer learners some form of spatial and temporal freedom in work patterns. CBL is devoted to offering

- Editor's Note: 'Informal knowledge' is a term also used to refer to tacit or implicit knowledge used by humans in their professional activities and in this sense has nothing to do with machine readability. 


\section{I.P.F De Diana and T.N. White}

multiform and intensive approaches to the support of learning processes. Finally, EBs offer adaptable and highly accessible knowledge sources, usable as a foundation for curicula. We will discuss some of the synergistic potentials of the combinations.

\section{CBL combined with EBs}

CBL and EBs can enhance each other in various ways. Knowledge available in EBs can form the subject of study and CBL can offer options to acquire this knowledge in an efficient and effective way. The didactic support to be offered by CBL can be linked into EBs by means of additional modules and specific learning support tools, such as exercises, examples, summaries, simulations, questions, and so on. Otherwise, CBL programs can be contained as part of the materials of EBs or CBL programs can be linked, in the same way as other computer programs.

\section{EBs combined with CSCW}

CSCW in combination with EBs can offer attractive options for learning. CSCW can enhance the use of EBs as EBs can offer the specialist knowledge sources, to be used as resources for structuring the work of a group of learners in a 'natural' and transparent way. In this we assume a situation in which a group of learners, say a study group, centres its activities around a large body of study material, and in which electronic mail is used as a carrier for data exchange.

\section{CSCW combined with $C B L$}

The combination of CSCW with CBL offers remarkable opportunities. There is much literature which supports the value of cooperative learning (e.g. Johnson \& Johnson, 1987). It is suggested that learning in general can be optimized by combining individualized learning and competitive learning with cooperative learning. This is a remarkable finding from the perspective of CBL.

Traditionally CBL has been promoted as an individual approach to study and learning, adaptation to the individual being the major contribution of CBL. Cooperative learning, involving cooperative problem solving, cooperative product development, and cooperative writing, is not emphasised in traditional CBL. In fact, several of the well known CBL paragigms can be adapted to become suitable strategies for group-based learning, for example by offering options for group-based solving of design exercises or by the use of cooperative gaming techniques. 
What is an educational SuperInterface?

\section{A definition and a place in a metaphor}

The term human-machine interface is well established. In using this term we focus on how the user of a computer can communicate with the technical system and in particular with the software that structures communicative activities.

The emphasis in the definition of a SuperInterface is to be placed on the organizational side. A SuperInterface defines the totality of organizational and technical facilities serving a community of computer users for cooperative and communicative purposes in order to reach both common and individual goals. A computer network serves as the technical foundation to reach such goals.

In order to make the concept of a SuperInterface more explicit, we can extend the metaphor of the Info Highway at little bit further. A future Info Highway serves to create a flow of information to (and from) information processing units, be it households or organisations. The Info Highway then can be compared with a local area network (LAN), connecting information processing nodes in a network. Within such a LAN, the transport of information can be organized to meet specific needs. In addition, a SuperInterface takes care of the way in which information is distributed to the processing and memory unit(s) of the network and arranges communication between these units. It is therefore not only the collection of processing units (a role we ascribe to the organisation) or the collection of memory units (a role we ascribe to the information storage parts, that from an organizational point of view can be labelled as 'organizational memory' (Conklin, (1992)). A SuperInterface embodies the information logistics of a LAN-based organization. But what makes a 'SuperInterface' 'Super'? We can offer several reasons.

In the first place, such an interface is not an interface between one person and one machine; rather it connects a number of parsons and a number of machines together.

Secondly, such an interface has to deal with extensive processing of information: receiving information into the organisation, filtering information, permuting information, distributing information, routing information toward addressees, sending information out of the organisation, and so on.

In the third place, such an interface is large, extensive, and distributed in its mode of information processing. It is made up of a number of information processing networked processors (call them nodes), working together in processing and mediating information flow.

What is an educational SuperInterface made of?

An educational SuperInterface is a specific type of SuperInterface. It has to serve education, that is to say it has to foster the transfer of information and knowledge and to support human learning in networked learning 
environments in which people and machines communicate and cooperate to reach learning goals.

Merely defining an educational SuperInterface will not serve to clarify its functions and structure. It is constructive to indicate globally the hardware and software facilities that are necessary to create even an elementary prototype. It should be noted, that we approach the concept of an educational SuperInterface from the perspective of the three technologies which we identified earlier; other perspectives are probably feasible too. Furthermore, we are convinced that technical issues, such as hardware and software, are considerably less important than organizational issues in building Superinterfaces.

\section{Hardware}

It is necessary to have a computer network with adequate facilities to process multimedia files. Large background memories (preferably rewritable optical discs) are needed so that it is possible to store and manipulate voluminous documents.

\section{Software and groupware}

An educational SuperInterface is conceived of as an 'open' software system; that is we believe that the software making up the interface should be easily extendible. We expect the followirg software items to be important.

- Basic software for distributed data processing and distributed data management (Malone et al., 1988).

- Database software for storing, manipulating, and retrieving multimedia data, either organized in electronic documents or not.

- Hyperdocument software (for building and using) which allows the storage of educational information in EBs.

- Interactive software tools to be used by teachers and learners for annotation, referencing, linking of external programs and information, and so on in relation with EBs.

- Electronic mail software which serves to send, filter and receive, messages, data files, audio and video files, and computer programs. Preferably we would like to have 'augmented' mail that offers options for connections between mail modules and application packages. Such mail would offer special facilities for 'workgroups', as well as facilities for workflow modelling and workflow management (Lai, et al., 1988).

- CSCW software which is 'standard' applications software usable in the 'working together' $\mathrm{CSCW}$ approach, and software that has been designed for the 'working simultaneously' approach (Olson et al., 1990), both of which can be called 'groupware'. Such application software should be linkable both to mail facilities and to database or hypermedia ESBs.

- $C B L$ development software to include authoring tools for adaptable CBL products that are suitable for a CSCW approach and for the use of ESBs. Research on environments for the development and use of adaptable CBL products has been reported widely (e.g. De Diana, 1988; De Diana \& de Vries, 1990). 
- Data capture software for educational evaluation which permits the automatic logging of learning behaviour of individuals and groups of learners; it offers teachers and learners quick and easy overviews of study results and the quality of study materials (e.g. the software tool described by Volman and De Diana, 1993).

- Educational management software which generates management information to support the analysis of the efficiency and effectiveness of SuperInterface-based education and educational processes.

- Usability analysis software for SuperInterface systems enabling the analysis of the adequacy of the various system functions and how they interact with each other.

\section{SuperInterface: learners, teachers, and organisations}

The introduction of educational SuperInterfaces might strongly influence the organization and processes of knowledge transfer.

In our discussion we have linked three technologies together and we have situated them in the context of education. Tuning of technologies to each other and their purposeful linking into a learning environment seem to be the key ingredients in establishing SuperInterfaces.

As the basic technological ingredients are available, and linking and tuning are technically possible, SuperInterfaces can become available, but are they desirable? This question can be posed from three different points of view: the learners, the teachers, and the educational institutions.

\section{Learners and the educational SuperInterface}

For the learners, the desirability of an educational SuperInterface concerns logistics, quality of study materials, mode of study and the effectiveness and efficiency of work.

An educational SuperInterface might give learners a fair degree of freedom in deciding location and time of study. As the study materials are not intended to be purely text and, to some extent, of an interactive nature, SuperInterface as a learning environment might be more rich, more varied and flexible than the traditional learning environment: the textbook. Electronic study materials can be kept up to date, can be tailored to individual needs, and are expandable. Experience with $\mathrm{CSCW}$ might prove valuable in learning to cooperate with others in cognitive endeavours. We might expect that the SuperInterface learning environment is a sharply focussable environment but one which offers a considerable number of options for obtaining feedback from peers and teachers. But, as loggings are made of study behaviour and as study results are registered, the SuperInterface can offer individual feedback to help a student to analyze his own work and study results. Focussed study can contribute to educational efficiency, while regular and varied feedback can improve the effectiveness of education. 
100 I.P.F De Diana and T.N. White

\section{Teachers and the educational SuperInterface}

From a teacher's point of view important issues are the logistics of education, options for manipulating study materials, mode of teaching, and the effectiveness and efficiency of education.

A SuperInterface should allow teachers to offer learners a high degree of freedom in deciding location and time of study. Teachers will have considerable means available to organize and structure study materials in accordance with their own ideas. It will be easy to create variety in study materials. Likewise, it will be easy to renew, extend, or otherwise adapt materials. CSCW can change the nature of teaching from a classical one-way approach to a multiway communication process. Extensive and automated loggings will support teachers in the mental modelling of study and cooperation processes. Electronic mail and workflow software will help them to be informed about the actual learning processes and to offer feedback in a differentiated, fast and efficient way.

\section{Organizations and the educational SuperInterface}

An organisation can benefit a great deal from using an educational SuperInterface in expanding its opportunities for knowledge transfer to support distance teaching. As study materials are accessible by means of computer networks, the use of materials need not be limited to the primary end-users, that is enlisted students. Just as a traditional library can offer lending service to users of other libraries, the SuperInterface might be accessible not only to enlisted students, but to any person interested to receive information about study materials which are available. Thus an important public service can be created. By using software for structuring group membership, it is possible for a teacher to decide what parts of the study material, if any, should be accessible for the general public.

The information infra-structure of an organization that uses a SuperInterface is almost unlimited. Besides the three basic technologies identified, such an organization can integrate others into its infra-structure, such as technology for electronic publishing, for teleconferencing, and in fact, most of the services included in the Info Highway package.

By using such technologies, an educational organization might become extremely flexible, pluriform, and attractive for its students, while adequate logging facilities would offer the organization an easy way to itemise the educational services utilised.

\section{Organization and innovation}

Our present day society is increasingly influenced by developments in information technology. Direct satellite connections via the cable network, automated bank tellers, computer-controlled car engines, CD-players, teletext, fax and viditel: they are all innovations stemming from the last five to ten years. The introduction of these developments has been received without much social commotion and users apparently experience them as 
meaningful and incorporate them without much effort in their world of living.

The lack of social opposition arising from the introduction of many technological developments at the level of the individual end-user contrasts with the multi-faceted set of problems that technological innovations often cause in social organizations. In various industries sometimes real tragedies take place as a result of industrial innovation based on high-tech automation and computerisation. Personal take time to adapt; they require additional education and training which is frequently not taken into account or underestimated in terms of time and cost. Staff are often expected to meet production targets despite their lack of training.

In many cases a set of problems become visible that is a consequence of implementing new technology in organizations that are not prepared for it. There is an overwhelming argument for planning in advance to make the possibilities of advanced technologies and methods fit the organization, most importantly, its people. Crowston and Malone (1990) present different perspectives on this set of problems. In the Human-Computer Interaction literature, the acquisition of 'job analysis data' before development and 'usability testing' are stressed (Gould, 1990; Spenkelink et al., 1990). The introduction of SuperInterfaces must also be considered from this perspective.

\section{Research issues}

SuperInterfaces could be build from available technology. Most likely, they will evolve slowly. In order to be able to design such interfaces, we need research and model construction of important interface components and the interrelations between them.

Some of the educational research issues are:

- research into the modelling of Electronic Study Books: the study of book architectures (for example see the work of Richards et al. (1991) into Page Structures for Electronic Books), book interface and book user models, and cognitive book support tools;

- research into the modelling of educational workgroups: the study of communication protocols, workflow modelling and support, filtering approaches and models, and so on;

- research into the options for combining CBL types with Electronic Books: we would like to have dynamic information interchange between book parts and CBL forms;

- research into the combination of $\mathrm{CBL}$ types with $\mathrm{CSCW}$ : in fact most known CBL types seem to be extendible into CSCW format, but how and in what ways?

- research into the automated collection and analysis of communication data for educational CSCW: data collection strategies, evaluation models, and interpretation frameworks. 
Results stemming from research and modelling of such educational topics would allow us to properly design (parts of) usable educational SuperInterfaces.

\section{Conclusions}

Related to the metaphor of the Info Highway, we have described and located the concept of an educational SuperInterface. This concept is provocative: it stresses conceptual limits and suggests some of the educational technology that can be with us in a decade, or less.

Such abundant information creates problems as well. Recently, the Dutch Universities made a financial agreement with publishers, allowing for the use of copied journal articles and parts of books in (paper) syllabi. The agreement came after a long and sometimes bitter struggle, and indicates the kind of problems that can be expected if electronic journals and books are distributed on a large scale through networks. Cutting and pasting, picking and mixing, that is all that is needed to create an electronic information sharing paradise - free for all. Of course, in this respect ideas and opinions will differ too!

Intriguing as the concept of an educational SuperInterface may be, the development of such interfaces will be difficult and take time. Difficult in that sense that we have basic technologies available, but that is not clear in various ways how to apply these technologies properly to education in an integrated way. We have been discussing research issues that can help us settle this problem, but again, research takes time.

So, we expect that the Info Highway will be established and transporting before SuperInterfaces are functioning properly. But, in time, we will see SuperInterfaces!

\section{References}

Barker, P. (1990) Designing electronic books. Joumal of Artificial Intelligence in Education, 1, 2, 31-42.

Conklin, E.J. (1987) Hypertext: An introduction and survey. IEEE Computer, September, 17-41.

Conklin, E.J. (1992) Capturing Organizational Memory. In Groupware '92 (ed. D.D. Coleman ) pp. 133-138. Morgan Kaufmann, San Mateo.

Crowston, K. \& Malone, T.W. (1990) Information technology and work organization. In Handbook of human-computer interaction (ed. M. Helander) pp. 1051-1070. NorthHolland, Amsterdam.

Dam, A. van (1992) Electronic Books and Interactive Illustrations. Transcript of a Talk. In Interactive Learning Through Visualization (ed. S. Cunningham \& R. Hubbold) pp. 9-25. Springer, Berlin.

De Diana, I.P.F. (1988) Het EDUC systeem: Aspekten van een methodologie, ontwikkelingsmethode en instrumentatie voor tutorieel Computer Ondersteund Onderwijs. [The EDUC system: Aspects of a methodology, development method and instrumentation for tutorial Computer Based Learning]. PhD Thesis. University of Twente, Enschede. 
De Diana, I.P.F. \& de Vries, S.A. (1990) Adaptable Educational Courseware: an antidote to several portability problems. Journal of Research on Computing in Education, 23, 2, 225-241.

Elmer-De Witt, P. (1993) Take a Trip into the Future on the Electronic Superhighway. Time, April 12, 50-55.

Flores, F., Graves, M., Hartfield, B. \& Winograd, I. (1988) Computer systems and the design of organization interaction. ACM Transactions on Office Automation Systems, 6, 2, 153-172.

Gaines, B.R. (1990) Knowledge support systems. Knowledge-Based Systems, 3, 4, $192-$ 203.

Gore, A. (1991) Infrastructure for the Global Village. Scientific American, 265, 3, 108112.

Gould, J.D. (1990) How to design usable systems. In Handbook of human-computer interaction (ed. M. Helander) pp. 757-789. North-Holland, Amsterdam.

Greif, I. (1988) Computer-supported cooperative work: a book of readings. Morgan Kaufmann, San Mateo.

Greif, I. \& Sarin, S. (1988) Data sharing in group work. In Computer-supported cooperative work: a book of readings (ed. I. Greif) pp. 477-508. Morgan Kaufmann, San Mateo.

Johnson, D.W. \& Johnson, R.T. (1987) Learning together and alone: cooperative, competitive and individualistic learning. Prentice-Hall, Englewood Cliffs.

Lai, K., Malone, T. \& Yu, K. (1988) Object Lens: A 'Spreadsheet' for cooperative work. ACM Transactions on Office Information Systems, 6, 4, 332-353.

Malone, T., Grant, K.R., Turbak, F.A., Brobst, S.A. \& Cohen, M.D. (1988) Intelligent information-sharing systems. Communication; of the $A C M, 30,5,390-402$.

Olson, J.S., Olson, G.M., Mack, L.A. \& Wellner P. (1990) Concurrent editing: The group's interface. In Human-computer interaction: Interact' 90 (eds. D. Diaper, D. Gilmore, G. Cockton \& B. Shackel) pp. 835-840. North-Holland, Amsterdam.

Richards, S., Barker, P., Giller, S., Lamont, C. \& Manï, K. (1991) Page Structures for Electronic Books. Education \& Training Technulogy International, 28, 4, 291-302.

Spenkelink, G., van Spijker, H. \& White T.N. (1990) Evaluation of flat panel display properties on a high fidelity display simulator. In Human-computer interaction: Interact' 90 (eds. D. Diaper, D. Gilmore, G. Cockton \& B. Shackel) pp. 721-724. North-Holland, Amsterdam.

Volman, C. \& De Diana, I. (1993) Courseware Evaluation and Decision Support Based upon Courseware use. Educational \& Training Technology International, 30, 3, 255266. 